\title{
Western Thoracic Surgical Association 2013 presidential address: Winning the HITECH challenge
}

\author{
John C. Chen, MD
}

It is heartwarming for me to be presented to you by Tom Burdon, a distinguished colleague and sincere friend. A "thank you" to Bobby, our immediate past president for his leading our strategic planning. I want to thank you all for joining us as we celebrate a wonderful tradition: the address of a new president. Your presence honors the Western Thoracic Surgical Association (WTSA), which members affectionately refer to as the Western. WTSA is an association that has been strengthened throughout its history by upholding the highest values of science, integrity, collegiality, and openness to people from around the world. By being here today, you are stating your desire for us to continue embodying everything that is good and principled about self-learning. I humbly recognize that I am just the guardian of something much larger than myself and much larger than all of us. I am the temporary guardian of an organization that means so much to so many, and, in that capacity, I sincerely thank you all for being here. I want to offer a special greeting to those families present, which are among WTSA's friends-you are the great force who lives out our dreams. I am deeply grateful for the company of our many distinguished colleagues from all over the world. We need you here, of course, to make the day seem properly serious. It is good to confirm that the presidents of the WTSA do look presidential in their roles as I am trying in mine. I must express how honored I am to have been so chosen: As a simple, community cardiothoracic surgeon. Fifteen years ago, I became a member, and like most initiates, I knew surprising little about the "Western" culture. I distinctly recall wearing a suit and tie at my first scientific session, and I believe I have not sported another at our annual meeting until today. You might wonder why I dressed the way I did: As a new member attending his first ever Western meeting, I erroneously assumed STS (Society of Thoracic Surgeons) etiquette! Let me again welcome our 19 new members of 2013 and invite them to participate in the discussions throughout our stay in Coeur D'Alene.

\footnotetext{
From the Division of Cardiothoracic Surgery, Hawaii Permanente Medical Group-University of Hawaii School of Medicine, Honolulu, Hawaii.

Disclosures: Author has nothing to disclose with regard to commercial support.

Read at the 39th Annual Meeting of The Western Thoracic Surgical Association, Coeur d'Alene, Idaho, June 26-29, 2013.

Received for publication July 9, 2013; accepted for publication July 12, 2013; available ahead of print Sept 9, 2013.

Address for reprints: John C. Chen, MD, Division of Cardiothoracic Surgery, University of Hawaii-Kaiser Permanente Hawaii Region, 3288 Moanalua Rd, Honolulu, HI 96819 (E-mail: JChen@alum.mit.edu).

J Thorac Cardiovasc Surg 2013;146:1006-15

0022-5223/\$36.00

Copyright (c) 2013 by The American Association for Thoracic Surgery http://dx.doi.org/10.1016/j.jtcvs.2013.07.035
}

A presidential address is a privilege accorded to few, and the only occasion at which the choice of the topic is entirely up to the speaker and the content is not reviewed by a program committee. Perhaps the only restriction advised is that one would direct the discourse toward something the speaker knows about firsthand. As I researched suitable topics, I learned that history has been done well at previous meetings, also biography, surgical education, and health care reform. I concluded that it would be best to address you on a subject of urgency and one that I have spent the past few years struggling with-relevant learning in the era of big data. We live in evolving times, particularly as related to our chosen profession of thoracic surgery.

Despite the remarkable clinical advances that have occurred during the past century, monumental changes are upon us; I find it hard to believe the heart and lung machine is 60 years young this year. A recent, rapid convergence of ideas in digital medicine has the potential to provide a better health delivery system for our nation. The uniqueness of the surgeon will be invaluable during this evolution. Surgeons think and work differently; we are not interchangeable with internists, physician assistants, nurse practitioners, or hospital administrators, even though we are all essential members of the 21st century surgical team. Back in 1999, remaining in a full-time academic environment posed unique challenges: Medical schools lacked funds, and dedicated research time was disappearing rapidly. I was lucky to be offered the opportunity to completely internalize the Hawaii Kaiser Permanente Thoracic Surgery Program. Back in those days, our corporate preferred Web browser was Netscape, and the company E-mail system did not accept attachments, so I kept my college E-mail address that I still use today. In fact, a young "JChen12" (2012) at MIT recently sent me a message, hoping to figure out who has the "JChen@alum. mit.edu" address. E-mail afforded me the ability to continue collaborations across the Pacific Ocean without the delay of "Par Avion." I believe everyone in this room today has a thoughtfully chosen E-mail address, but the increase in Internet traffic has made communication more difficult. Ten years ago, I looked forward to checking E-mail; today, it has become a daily deleting and reporting spam expedition.

Since I was born in Taiwan, let me start with a couple of Chinese characters. It is traditional to read right to left.

險危一Danger

會機_Possibilities or opportunity

The other thing the Chinese do is read from top down. 危機—Critical turning point or crisis 
To this day, I am convinced this is why I have shuffled English grammar. In Proust and the Squid, Maryanne Wolf theorizes the act of reading Chinese characters has shaped the Chinese reading brain, and that a person who learns to read in Chinese uses a particular set of neuronal connections that differ from the pathways used in reading based on the alphabetic principle. ${ }^{1}$

When written in Chinese, the word "crisis" is composed of 2 characters: One represents danger and the other represents opportunity. This play on words probably gained momentum when John F. Kennedy delivered a 1959 speech in Indianapolis. The usage has since been adopted by business consultants and has attracted attention in universities and the popular press.

I truly believe US health care is the best in the world, but our spending has been increasing faster than the incomes of most developed countries, which raises questions about how we will pay for our future health care needs. Our health care system is at a critical turning point, and we are in need of an innovative fix. At the 2012 Clinical Congress of the American College of Surgeons, much discussion focused on the continual increase in US health care expenditures and implementation of the "Patient Protection and Affordable Care Act," commonly abbreviated as the "ACA for Affordable Care Act." Recent data from the Organization for Economic Co-operation and Development (OECD) reveal the United States has the highest growth per capita health care spending of the 15 countries that rank in the top three fifths of national income. The Organization for Economic Co-operation and Development is an international organization that collects and analyses data based on various social and economic indicators.

We would agree that if the United States in this graph were a stock in the Standard and Poor's 500, we would all invest in this company first thing tomorrow morning; however, this is our rising health care expenditure for the past 4 decades and unsustainable. How many of you have received E-mails to click for repeal of the "sick" Medicare Sustainable Growth Rate (SGR)? How many of us have actually done so or taken an interest in the details? Less than one fourth of STS members who receive action alerts click through to send messages to their members of Congress about any aspect of health reform legislation. We need to click to better health care. Every year since 1997, the Center for Medicare Services has sent a report to the Medicare Payment Advisory Commission, which advises US Congress on the previous year's total health care expenditures. The report includes a conversion factor that changes the payments for physician services over the next year to match a target annual SGR formula. If the expenditures for the previous year exceeded the target expenditures, the conversion factor will decrease the payments for the next year. On March 1 of each year, the physician fee schedule is updated accordingly. The implementation of the fee schedule to meet the target SGR can be adjusted by Congress, which has been done regularly in the recent past. A last minute adjustment can be characterized as paying the minimum on our credit card bills and allowing the principle to accrue and compound interest debt. How many of us would choose to do this with our credit cards indefinitely? Physician groups such as the American College of Surgeons and STS have been lobbying to Congress for SGR reform and need our help. We must first take interest, if we are to take action.

At this year's STS meeting in Los Angeles, Dr John Mayer suggested that we support specialty-specific SGR. One of the highlighted SGR flaws is the concept of collective accountability; all providers face the same fee changes, regardless of their spending. A study in the New England Journal of Medicine last year estimated excess SGR target spending by selected specialties. ${ }^{2}$ Cardiothoracic surgery is one of the highest valued specialties in the SGR formula. The STS political action committee has proposed the following principles for specialtyspecific reform of the SGR formula:

1. The physician payment system should ensure that individual medical specialties can control the growth rate of their services and payments by identifying the most effective and appropriate treatment for the patient.

2. Specialties should not be penalized if their quality and value improvement activities result in lower Medicare expenditures, otherwise known as the gainsharing initiative.

3. The STS National Database should be used in sharing outcomes data to allow physicians to change their practice patterns to achieve better results, more efficient delivery, and increased patient value.

Government legislators act only in times of crisis, as reflected by Congress' approach to save ourselves after going over the fiscal cliff this past New Year's Day. We need to take action with the SGR and support regional health care reform events when the opportunities arise. When you volunteer to help with reform, it does not matter how fast you go, so long as you do not stop. Government service can be risky to the reputations of those who volunteer, but knowing that you can go back to surgery is empowering. Physicians early or late in their careers often have supportive health systems to return to. Young surgeons can return to junior faculty positions or practices and resume the climb up the career ladder to which they aspire. Their service will be seen as an extension of professional development. More senior surgeons will often have acquired standing in their community that provides them considerable professional security.

There will be emerging opportunities and dangers to physician practices and health care delivery for all Americans. This 
will be due in large part to the continued enactment of the Affordable Care Act (ACA) and a projected physician shortage. This, I believe, is an example of a reverse innovation. Very simply, a reverse innovation is any innovation likely to be adopted first outside the United States. It is so-called because historically nearly all innovations have been adopted first in rich countries. It has been argued that reverse innovation will become more and more common, and that it presents a formidable organizational challenge for incumbents in the developed world. Reverse innovation is not synonymous with disruptive innovation. A disruptive innovation has a particular dynamic that endangers the incumbents. Typically, a new product has 2 primary dimensions of merit (eg, A and B). "A" could be quality and "B" could be service. Mainstream customers are mostly interested in quality, but a minority of customers will value service more than quality. The disruptive innovation, at launch, will be weak on quality but overdeliver on service. As such, it attracts only the minority. Because mainstream customers do not want it, incumbents tend to ignore the new entrant and the new technology. However, over time, the technology improves and the innovation becomes better and better at quality. Eventually, it meets the needs of mainstream customers on dimension quality, and, because they also place at least some worth on service, they choose the new product. The incumbent is suddenly disrupted; they have ignored the new technology all along. A good example of this is the Apple iOS operating system's lower spam index compared with Microsoft Windows. When quality improves for a lower price, economists term this increased value in mathematical terms:

$$
\text { Value }=\text { Quality } / \text { Price }
$$

One of the unarguable goals of the ACA is to add value to our health care system.

Whether a product innovation is disruptive or reverse, or both, it is difficult for an organization to execute a change in established practices. For reverse innovations, companies must overcome resistance to shifting control away from the headquarters and status quo. For disruptive innovations, companies must overcome the initial resistance to prioritizing an investment that does not interest mainstream customers. Also, if they do invest, they must overcome the fear that the new product might cannibalize the existing business. However, despite these difficulties associated with change, the vast majority would agree that the US health care system is not sustainable and that we are in need of an innovative fix.

Disruption has been the new mantra of our lives this decade. To get at the root of disruption, I would like to discuss Disrupting Class, by Clayton Christensen, for a few minutes. ${ }^{3}$ Although this is a book about the modern challenges of residential higher education, I believe the concepts are central to our experiences with the ACA. Historically, there has been a similarly inelastic economic demand for both higher education and health care. In the section of the book titled "How to implement computer based learning: Lessons from Rachmaninoff," Christensen asks us to imagine what would be if RCA Victor, the early pioneer of the recording industry, had marketed its products to be played after intermission of a live symphony concert to allow the performers to go home early. The theater audience would have been delighted with the sound quality of the Victrola phonograph but would have been deeply disappointed when the Rachmaninoff recording was pitted head-on against the live musicians. Fortunately for the recording industry, RCA Victor sold its phonographs to people who could not go to Carnegie Hall. Today, nearly everyone hears most of their music through recordings as opposed to in person. Quite simply, disruptive innovations can be summarized as those new technologies that cater to a social class that believe any innovation is more than they have; in contrast, a sustaining innovation targets those that always want more than they have. In Disrupting Class, Christensen also related disruptive innovation to the modern day and inferred that the World Wide Web has allowed us to customize how we learn. He has urged us to seize the opportunity to reap the benefits of such innovation; whether we learn best through linguistic, math (logical), spatial, bodily (kinesthetic), musical, naturalistic, or interpersonal methods, the Internet has provided us a portal to these resources at all times. He hypothesized that when an educational approach is aligned with one's intellectual aptitudes, understanding can come with greater enthusiasm and more easily.

The ACA will urge us rapidly to enroll 20 million "disruptive" Americans with income gaps into our health care system through the establishment of health insurance exchanges. These will increase the need for a new infrastructure of doctors and exacerbate an ongoing physician shortage. This shortage of doctors is also driven by the rapid expansion of Americans older than 65 and a 13-year freeze of Medicare support for graduate medical education. Together, these factors are expected to produce a projected decrease of some 91,000 physicians compared with our current workforce by 2020 . Data have shown a $7 \%$ decrease will occur during the next 10 years in many surgical subspecialties, including thoracic surgery, urology, and rural general surgery. The ongoing physician shortage has been exacerbated because initiatives to improve both quality and cost of health care through novel care models and implementation of electronic medical records (EMRs) have caused dismay among our senior colleagues.

The "Health Information Technology for Economic and Clinical Health" (HITECH) Act portion of the ACA is currently being enacted. Among the many goals, this ACA bill targets increased use of health information technology by requiring the government to take a leadership role in developing standards that allow for the nationwide 
use of EMR to improve quality and coordination of care. The bill stipulates an investment of \$20 billion in electronic infrastructure and Medicare and Medicaid incentives to encourage doctors and hospitals to digitally exchange patients' medical records. The fundamental question is: what universal mechanisms can be developed to influence current physician practice to add value and achieve the goals of better care and better community health? As a result of this legislation, the Congressional Budget Office has estimated that $90 \%$ of doctors and $70 \%$ of hospitals will be using comprehensive EMRs within the next decade. A recent survey from the Centers for Disease Control showed physician adoption of EMRs was ahead of projections.

The HITECH Act legislation provides immediate funding for computer training, dissemination of best practices, telemedicine, and clinical education to promote health information technology. In addition, the legislation has provided significant financial incentives through programs to encourage doctors and hospitals to adopt and use certified EMRs. Physicians are eligible for up to $\$ 65,000$ in reimbursements for showing that they are meaningfully using health information technology through the reporting of defined quality measures. I respectfully submit that we must take action in leading the definition of meaningful quality measures in thoracic surgery. If we do not determine our future, someone else will. In 2005, the possibilities were great, and our medical group began creating the virtual fourth space; we went all in with the HITECH Act in 2009. The risk we took with populating the digital fourth space was screen monitor fatigue and what we later estimated to be $10 \%$ of our senior medical staff's elected retirement as soon as they were eligible for their benefits.

Ultimately, the changes on us could require many surgeons to align with health systems to achieve national quality initiatives and secure cost reductions and economic stability. I must admit that at times it really seems we have lots of information technology but no relevant information. The implementation of computerized medical records has been a 40-year story for our health plan. It was a vision of Dr Sidney Garfield, the physician responsible for creating the Kaiser Permanente medical care delivery system. Since inception, Dr Garfield fought for the fundamental principle that physicians must be involved and responsible for administrative decisions that affect the quality of the care they provide. He published this concept and that of a computer center in the April 1970 issue of Scientific American. ${ }^{4}$ EMRs later gained widespread public attention some 30 years later when President George W. Bush in his State of the Union speech called for digitizing the national health records. There is much organizational memory surrounding the adoption of the Kaiser Permanente computer center. I actually believe the "computer center" is a misnomer: according to the Merriam-Webster Dictionary, to "compute" is to determine by mathematical means or calculate. When is the last time you used your computer to compute? I believe Dr Garfield's vision was a knowledge management center. Hawaii Kaiser Permanente was the ideal test site for EMRs because of our patient population and medical group size. Our first experience with EMRs was with an IBM product in 1999 that did not perform as anticipated.

Using HITECH to foster efficient health care delivery is an important component of the ACA, but where are the savings? A study in JAMA 2012 assessed the association between online access and the use of clinical services. Several previous studies have suggested that online access could replace a patient's need for face-to-face health care services. ${ }^{5}$ Patients with online access and E-mail communication demonstrated an unexpected increase in the use of in-person and telephone clinical services. In the year following activation, represented by the "zero" line, members with such access had increased rates of office visitations, telephone encounters, and acute cares services compared with a matched cohort of members without online access. These findings were consistent in both younger and older individuals and for those without chronic health conditions.

The Institute of Medicine recently asserted, "Clinicians increasingly are barraged with a vast volume of evidence of uncertain value." The availability of a large amount of information in integrated electronic databases can provide a quantitative basis for evaluating treatment outcomes, but it is up to us to synthesize it. By combining patient data in shared registries, we can correlate demographic variables with operative results and long-term survival. We recently queried the Epic Kaiser Healthconnect EMRs, administrative databases, and the Social Security Death Index to assess the 10-year patient survival after more than 3000 mitral valve operations among 4 cardiac surgical centers in California and Hawaii and encountered a few surprising findings.

Our publication this spring showed that, despite increasing recent implants of tissue valves, we found better 10-year Cox regression-adjusted survival after mitral valve replacement with a mechanical prosthesis in patients both younger and older than 65 years of age, leading us to the hypothesis that 75 might be the new 65 (available at: http://www.thepermanentejournal.org/ files/Spring2013/MitralValve.pdf).

I chose this example to demonstrate an important mathematical concept: The distinction between correlation and causation. Understanding the difference is perhaps best described in The House Advantage, by Jeffrey $\mathrm{Ma}^{6}$ (some of you might recognize his name from the movie Twenty-One). During the information revolution, 2 "camps" have emerged-the "computer people" and the "scientists." 
The computer people tend to focus on data mining and patterns that can be correlated. The scientists believe in the causal power of fundamental testing. The problem with large data sets is that they can be quickly analyzed in a variety of ways through today's computing software and patterns can quickly emerge, but these patterns can be misinterpreted as stemming from a fundamental cause rather than from random chance. Computer people do not necessarily concern themselves with whether the relationship they discover is truly causal. Let me provide an example: Hypertension and cardiovascular disease is causal, but it is also correlated, because people with hypertension have a higher incidence of cardiovascular disease. Many hypertensive patients eat "pommes frites"; thus, hypertension and eating French fries are often seen together and therefore are correlated. However, eating "pommes frites" does not necessarily cause hypertension or vice versa. There are many computer people today, but we surgeons are, first, scientists by training. We must take interest in the scientific validity of the computer people and seize every opportunity to challenge their interpretation of our practices.

Care of the surgical patient is an amalgamation of cognitive thinking, technical ability, and clinical judgment. Years of training are required to achieve the synergy of skills necessary to earn the trust of the patient in need of operative care. Traditionally, the patient-surgeon interaction has been managed as a private bond based on trust and mutual respect. As the American health care system has evolved, however, numerous extrinsic factors have radically changed this relationship. Expanding administrative "clicking" has robbed clinical time from health care providers and patients alike. Increasing productivity demands by a financially challenged health care delivery system has turned the surgeon-patient interaction into a time-limited check list encounter that plants the seeds of stress and mistrust on both sides. More than 13,000 health and medical apps are available for mobile devices. Information was power before the advent of the smartphone, but trust and judgment will be the currency of the digital era.

As you can see, the risks are great. But I promised you that I will focus on the opportunities-and I believe the opportunities are even greater than the risks. The pressures of cost and the potential of the HITECH Act are presenting all of us in medicine with a historic possibility: The possibility to better serve society by reinventing what we do and how we do it. It is an opportunity we must capitalize on. Let me be clear: Of course, we need to help contain costs and continue to seek greater efficiency. Of course, we need to continue to provide excellent surgical care. However, history has assigned us an even bigger challenge- $\mathrm{a}$ challenge that requires a solution of great commitment and scale. How do we put all of this together; how do we synthesize the vast amounts of information coming at us? Let me suggest that we must first remember what it is that we do. Googled facts, deception, and fantasy throw speed bumps at the surgeries we are asked to do. Uncertainty is the enemy of confidence, and, without confidence, we cannot perform thoracic surgery. Danger is at every turn in the operating theater. More important than ever, we must take time to explain what is relevant and important. One problem created by the information tsunami, especially for analysts, is that too much information is available. An informal social contract that exists among many virtual communities is that people act as software agents for one another. The agreement requires virtual citizens to keep an eye out for one another's interests, whom they never plan to meet, while they explore new sectors of information. The bureaucracy of the big data environment will challenge our surgical culture of face-to-face interactions.

Operating in a corporate environment is not in most medical school curricula, but winning in competition and liking challenge are at the cores of our specialty. Working in a large corporation has been well described by former CEO of General Electric, Jack Walsh, in his book titled Winning-a must read if you are contemplating long-term contracted employment. I would not do Mr Walsh justice by speaking about his chapter on Winning during a crisis in this address, but will refer you to the YouTube link (http://www.youtube.com/watch?v=PxU6Z0BgyWM).

"That which does not kill us makes us stronger" is a quotation by the German philosopher Friedrich Nietzsche (and not a song by Kelly Clarkson, even though she owns the Grammy Pop Album of this year). Nietzsche also professed that our way of thinking changes through way we live and through the tools we use. Adapting to the HITECH Act did something funny to my brain-it made it more "Internet-smart." Functional magnetic resonance imaging studies by Small and colleague ${ }^{7}$ titled "Your brain on Google" compared the "Internet-savvy" and "Internet-naive" brain. There are 2 different schools of thought on their findings. One is that when you first embark on an Internet search, you require greater activity and more judgment, and that one would expect higher levels of activity, as if you were learning a new task. What their results showed is that while Googling for the best restaurants, savvy people actively engage decisionmaking areas on functional magnetic resonance imaging but Internet-naïve people can be overwhelmed by the situation and just read it as they would a book-they are not trying to integrate all the available information. The other interpretation is that Internet-naïve people just have a different pattern of wiring in their brains from those who are Internet-savvy - that is, people who prefer using the Internet and enjoy that mode of reading are wired differently from the Internet-naïve people. We could not 
distinguish that in their study. I believe adapting to the HITECH Act might have transformed my brain from simply reading information to synthesizing what is relevant online and that the HITECH Act will entice you to learn by empirically searching for the right buttons while you are checking on your patients at $4 \mathrm{AM}$. One thing is clear, the Internet-savvy brain during a Web search uses energy and mental fortitude. A real need exists to carefully manage yourself with adoption of the HITECH Act. Most dreams in America originate in the bedroom-I would suggest choosing your pillow-top over your laptop as much as you can while the sun is down.

With the information tsunami approaching, what does an effective learning mind look like in 2013? Dr Howard Gardner $^{8}$ proposed a few cognitive abilities that will command a premium in the years ahead in Five Minds for the Future. Dr Gardner studied how the human mind is organized, how it creates, and how it leads for several decades. He introduced 5 "dramatis personae" that equip an individual to deal with what is expected and what cannot be anticipated. He hypothesized that "disciplined," "synthesizing," "creating," "respectful," and "ethical" minds will be needed to understand and control the myriad of contemporary forces coming at us. I would like to focus on synthesis, because making sense of the many screens before us has been challenging me lately. Syntheses require us to put together elements that were originally discrete. The most common techniques we use to synthesize information are narratives, taxonomies, concept theories, aphorisms, metaphors, and embodiments. Narratives exist in the fiction and nonfictional realm; the synthesizer puts the material in a coherent story form (eg, "The Tortoise and the Hare"). Examples of taxonomies are the Dewey decimal system or E-mails to take interest, take action, or take ownership. Complex theories tie together a blend of phenomena such as Charles Darwin's theory of natural selection or Pareto's Law of the 80-20 principle. Aphorisms such as "a team with high moral is difficult to defeat" or "when playing StarCraft, fear is not an option" help many folks acquire wisdom by emphasizing short "rule-of-thumbs." Powerful metaphors bring concepts to life by invoking vivid images. Sigmund Freud saw the "unconscious" as the region beneath the conscious thought, and the "id" as the horse that could jerk the "ego-rider." Embodiments of art illustrate ideas without words: Paul Gauguin's paintings at the Boston Museum of Fine Arts depict where do we come from, where are we, and where are we going. The achievement of effective synthesis is a considerable feat. Any effort to synthesize entails 3 ordered components: the what, the why, and the how. It is essential to not let the HITECH Act get in the way of doing what is asked of us and why we do what we do.

Interdisciplinary synthesis is perhaps synthesis in its most ambitious form; it requires complete understanding and demands contextualization. Today, genetic testing of a few milliliters of a mother's blood allows us to determine which child will likely develop atrioventricular canals or endocardial cushion defects. Although adults can decide whether to undergo genome sequencing, an unborn child cannot consent to knowing its genes. The question of whether to share this information cannot be left alone to the geneticist, physician, or minister. In the ideal situation, teams of geneticists, physicians, social workers, religious leaders, and ethicists should weigh in on this decision; however, there is no guarantee that individuals with different training will conceptualize the issues in the same way. "TEAM" is an acronym for "together everyone accomplishes more."

I would like to shift gears and focus on what it is that we do. A couple of years ago, we consulted with a 67-year-old woman with a $7-\mathrm{cm}$, enlarging descending thoracic aortic aneurysm. The patient underwent extensive counseling regarding open thoracotomy versus endovascular repair, and she chose the endovascular approach after an Internet search. She underwent thoracic endovascular aortic repair in September 2010 by way of a right iliac conduit and returned to full activity shortly thereafter. Serial follow-up chest computed tomographic (CT) angiography to evaluate the thoracic aorta revealed a type 1 endoleak. The patient underwent additional proximal and distal stenting repair of the type I endoleak the next year. She returned with an enlarging 9-cm aneurysm on the follow-up chest CT angiogram. What would you do with this M2S Preview (West Lebanon, NH) chest CT scan reconstruction-is this a type I or II endoleak? (Figure 1). After personal communication with Scott Mitchell, we performed an open total arch replacement under circulatory arrest using right axillary cannulation in April 2012. Figure 2 is an intraoperative photograph of the type I endoleak at the proximal landing zone of the Medtronic stent graft. Just behind the forceps is the origin of the subclavian artery (Figure 2). A follow-up chest CT scan earlier this year showed a now larger $10-\mathrm{cm}$ thoracic aortic aneurysm, and this is the picture of a distal type I endoleak. We discussed referring her to a center with more thoracic endovascular aortic repair experience to have the aneurysm repaired, but she wished to have the surgery done close to home so that she could be surrounded by her family. We repaired her distal endoleak through a left thoracotomy shortly after Easter this year, and she is recovering well.

The information tsunami will provide our patients with knowledge of new technologies, and they will challenge us to learn surgeries we have never done before. The promise of less invasiveness and the potential for lower morbidity will create complications that only thoracic surgeons know how to manage. We must take interest in minimally invasive cardiothoracic surgery and take responsibility for its outcome. The quality of our long-term results will determine our future. 


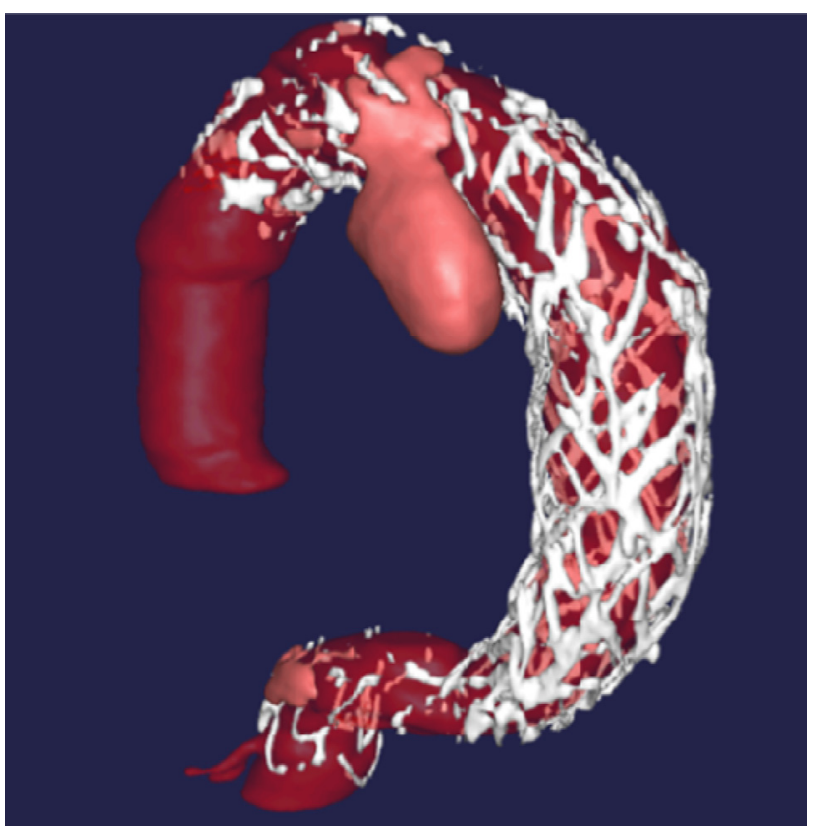

FIGURE 1. Chest computed tomography scan with M2S Preview (West Lebanon, $\mathrm{NH}$ ) reconstruction of an enlarging 9-cm thoracic aneurysm due to an endoleak.

We all see the world through the prism of our own circumstances. I happen to practice surgery in a modestly sized community hospital on an island in the middle of the Pacific Ocean. Our hospital serves as a referral center for other islands, including Maui, Kauai, Tonga, and Micronesia. The people we serve are mostly small-town folk and recent transplants. Most of them are very hard

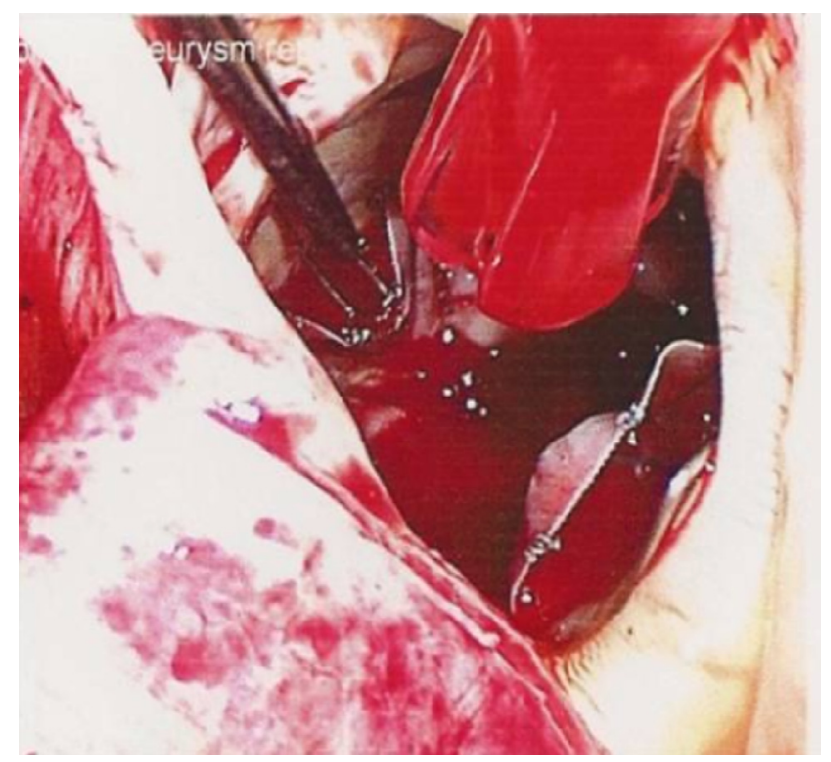

FIGURE 2. Intraoperative photograph of the type I endoleak seen in Figure 1 at the proximal landing zone of the stent graft. Just behind the forceps is the origin of the subclavian artery. working. Most of them are extremely grateful for the health care they receive. It has been a most rewarding experience to be a surgeon in the big city, but small town, of Honolulu. It has truly been one of my great fortunes. However, I believe that whether we practice in places rural or metropolitan, a university setting or a community practice, all of us share common traditions and values that bind us as physicians and surgeons: traditions and values that, in my view, we all should cherish as the backbone of Western culture. Yet, in today's world, one does not have to look very far to witness these values stretched and bent, at times to critical limits. I find this troubling, because I have always believed that what we do matters most - that how we act as individuals reflects on all of us.

British economist Julian Le Grand ${ }^{9}$ suggested that public policy is grounded in a conception of humans as "knights," "knaves," or "pawns." Knights are motivated by virtue, knaves are driven by rigid self-interest, and pawns are passive victims of their circumstances. A society's view of human motivation influences whether that society establishes public policies that are permissive, punitive, or prescriptive. Many recent health care debates, especially those related to health care financing and quality, have implicitly prescribed a view of physicians and their underlying motivations. Depending on the perspective, physicians have been characterized as being in practice for the betterment of society or for their own selfish gain; sometimes, they are even caricatured as automatons whose actions are defined more by external rules and regulations. I respectfully submit that the WTSA mission to educate in a collegial environment reflects a knightly culture.

During this past year, many colleagues have asked about the "culture" of where I practice medicine. The best example I have come across for explaining the complexities of culture is from a National Geographic DVD, The Whale That Ate Jaws, which has recently been posted on YouTube (www.youtube.com/watch? $\mathrm{v}=$ P6Si6BITmyA).

In brief, in the fall of 1997, at the Farallon Islands 27 miles off the coast of San Francisco, people on a whale-watching boat saw the very unusual event of a killer whale encountering a great white shark. This was the first recorded event of a great white shark meeting a killer whale. Because killer whales live in different groups that specialize in the hunting of usually either fish or mammals, depending on the available food source, the possibility that killer whales might have learned how to hunt sharks was the focus of this documentary. Biologist Samuel Gruber demonstrated tonic immobility by holding a young shark on its back so that the shark went into a trancelike state from serotonin flowing to its brain; because great white sharks require activity for oxygen intake, biologists believe a great white shark was suffocated by a killer whale's holding action. Perhaps, more importantly, they suggested that killer whales might have the ability to learn tonic 
immobility as a hunting strategy from each other. Orca whales are smart- they have different skill sets for different situations. Killer whales have methods of developing new hunting strategies, not overnight, but over years, and the strategy is passed from 1 generation to the next. Biologists call the set of resulting behaviors a "culture." There was no discussion of the effect of the body surface area on the outcome between great white sharks and killer whales, but size has a major influence on the Kaiser and Permanente culture. Size actually helps us.

In 1964, Dr David W. Merrill and Roger Reid began research to create a model that could predict success in management. What the partners discovered was that people's behaviors and actions are consistent. "Social styles" is the name of a particular psychometric instrument that helps people better understand and work with others through appreciation of their basic decision-making and control needs. On employment with Kaiser Permanente, everyone is instructed on the differences between driver, logical, expressive, and amiable personalities and how to best relate with these diverse personalities. During the course of our career, we might be asked to take on different jobs, depending on our professional and personal growth. One of Kaiser Permanente's corporate modus operandi has been guaranteed employability and not necessarily employment.

Hawaii has been characterized as a stew of many ethnicities: A place where diverse backgrounds are not only understood and accepted but also celebrated. I firmly believe this stems from learning to live together through repeated tsunami threats; our state is at the greatest risk of a tsunami. Hawaii experiences roughly 1 tsunami warning each year. Several of my friends have had to evacuate their beachfront homes emergently these past few years. California, Oregon, and Washington have a damaging tsunami once about every 18 years. What would you throw in your backpack if you had to evacuate unexpectedly? During a tsunami threat, times require that we stay together and watch out for one another.

The volcanic arcs and oceanic trenches that partly encircle the Pacific Basin form the so-called Ring of Fire. This zone, which is notorious for frequent volcanic eruptions, coincides with the edges of one of the world's major tectonic plates. When parts of the plate boundary slide past one another in opposite directions-such as the San Andreas Fault-minor earthquakes occur. The faults can also create cliffs thousands of feet high on the ocean bed. When 2 plates collide and 1 is forced under the other, the subsumed plate encounters high temperatures that melt solid rock. Some of this newly formed magma rises to the Earth's surface and erupts, forming chains of violent volcanoes such as the Ring of Fire. When an earthquake occurs under the sea, 1 side of the ocean floor suddenly drops downward, beneath the top edge of a subducting plate. The resulting vertical fault will generate a tsunami or giant wave.

The word "tsunami" is of Japanese origin meaning "harbor" and "wave" and is a word that was adopted internationally to represent the destructive waves caused by submarine earthquakes. In fact, the word "tsunami" began to replace the widely used misnomer "tidal wave" in the 1970s. Until that time, there was a great deal of resistance to the adoption of the word "tsunami" by the general public, and its use was limited only to the scientific community. However, as the Internet exploded in the mid-1990s, the term became popular with computerrelated businesses. The Internet suddenly became a powerful informational tool, and people likened it to the force of an ocean of previously unavailable information. After the devastating Indonesian Boxing Day tsunami of 2004, the word "tsunami" swept even further through popular culture and began being used internationally in several ways. However, the name itself was not perceived as inherently evil. Its usage was adapted metaphorically by people searching for an exotic word that evoked strength and power of a nonstoppable force. It is fascinating to me how certain words - in any language - have the ability to convey thoughts and meanings beyond those originally intended. What happened during the Japan Tsunami and Earthquake of March 11, 2011? Why did some people not evacuate but others did? The world held its breath during the nuclear catastrophe in Fukushima. This has led many to raise questions about strategies for risk reduction. With the most advanced tsunami warning system in the world, Japan has been a global standard-setter. But with the death toll nearing 20,000, it has also been at the forefront of reflections on how to improve risk preparedness. Lives were saved when children evacuated to higher ground, but they were also lost when people lost vital minutes by not taking the warnings seriously. Education, appropriate media, and information dissemination will have key roles to play. The World Bank has estimated that rebuilding the Fukushima tsunami-affected areas will cost more than $\$ 230$ billion and take years. The 2011 Japan tsunami has been estimated to become the world's most expensive disaster in history-our states continue to see the Fukushima tsunami debris wash ashore.

Today, we are connected from people around the globe. Forty years ago, we could have lived most of our lives surrounded by people who looked like we looked, believed what we believed, and saw the world the same way we did. But most of our encounters today are with people who think radically differently than we do. The shifting realities of our rapidly globalized information highways are well documented in The Worlds Is Flat, by Thomas Friedman. ${ }^{10}$ He wrote on November 9, 1989, "When the Walls Came Down, (Microsoft) Windows Went Up." This has been made no more evident than by the photographs taken at 
the signing of 2 landmark US health care laws in our lifetime. The first photograph is of when Medicare was signed into law on July 30, 1965, followed by the passage of the Patient Protection Affordable Care Act in 2010. "It takes a village to raise a child" is an old African proverb that could not be truer in our time of collective intelligence. Nelson Mandela has called it "ubuntu"-I am what I am because of who we all are. Hawaii has one of the highest penetrations of broadband access in the United States. Information sharing has become faster and the connections infinite on an island in the middle of the Pacific. Our state is finding itself at an identity crossroad. I believe the local majority still enjoys watching live hula, but Facebook is unarguably more prevalent, and YouTube will teach you to dance at your own pace. I would like to introduce Jeffrey $\mathrm{Wu}$, my partner, this is his first time attending the Western meeting, and John Lee, our physician assistant, who are in the audience today; without them I could not do what I do everyday.

Before concluding, I want to recognize a few role models I have had the opportunity to learn from throughout the years. I was fortunate to have met Robert Colman while a medical student at Temple Medical School. Bob is a world-renowned hematologist and a graduate of the Harvard Schools from beginning to end-some have called him Preparation $\mathrm{H}$. You might recall having seen his name next to Henry Edmunds in many of their collaborations. Bob believed in the ability of the individual and not the degrees after their names. He afforded me the opportunity to co-author my first publication on the mechanism of glycoprotein IIB/IIIA on platelet aggregation in the Journal of Biological Chemistry as a medical student. Samuel (Eric) Wilson taught me to be a surgeon. I was lucky to have matched in general surgery at Harbor-UCLA Medical Center where Eric was the Chairman of Surgery. Harbor-UCLA is a resident-run hospital, and Eric had the uncanny ability to get the residents to run things smoothly. To this day, I cherish those days in Torrance during which I had the autonomy to do well for the injured without shouldering the responsibilities of an attending surgeon. While I was at UCLA, I was fortunate to have operated with Julie Freischlag. I distinctly recall her helping me through an aortic aneurysm operation when the plane behind the aorta was tough to develop. When I suggested she come around the table to perform this dangerous maneuver, she passionately replied, "You can do this!" What can I say about Frank Hanley that you do not already know? Frank was the Chief of Cardiothoracic Surgery when I started at UCSF; he coached me through the search for that first position. I asked Frank about the most important elements in the contract, expecting him to give me a list of requirements. Frank's answer was surprisingly simple: he said, "The most important thing is the 'handshake'; you have to trust the person shaking your hand." I decided to pursue a university full-time position at UC Irvine, and that is where I learned to be a cardiothoracic surgeon. John (Jack) Connolly is a lighthouse in the sea of academia, and I would not be standing here if not for his mentorship. Scott Merrick and Mark Ratcliffe are the sustaining forces of UCSF cardiothoracic surgery, but I want to say a few words about Fraser Keith, who taught me the value of family. Fraser was one of my attending surgeons during my thoracic surgical residency. My wife, Lillian, went into labor just before one of our scheduled coronary artery bypass surgeries. Fraser without hesitation postponed the operation so that I could be there for our son's delivery. It was a memorable morning, and I am grateful to him till this day. I received a message recently that Fraser is now battling cancer; my heart really goes out to him.

I want to conclude by celebrating and thanking the good people of this world, while at the same time honoring a most important couple in my life. Each of you listening might recognize a couple like them in your own family, the kind of couple that dreams of a better life for their children. The couple in my story left Taiwan during the Vietnam era in America. This couple arrived with 2 suitcases, raised 4 children under difficult circumstances, but raised them with principles, with integrity and values, taught them neither malice nor hatred, taught them understanding and appreciation for different points of view, and taught them the value of education and hard work. I know myself some of what it feels like to be different; I have never experienced it after MIT, but I have experienced it. Out of the goodness of good people, this couple would eventually see their children to a better life than the one they had. Today, I want to honor everyone who dreams of a brighter future for their children and to tell each of them that there is hope-because the oldest son of the couple in my story eventually became the 37th president of the most remarkable cardiothoracic surgical association in the world.

Let me now close by telling our members: I come from you, and I am one of you. We share the same principles and values. To our new members and thoracic surgery residents: I hope the Western will become your second home; for Lillian and me, it will always be our home. To my kids, Allison, William, and Michael: never give up that curious spirit-I have learned more from you all than I could ever teach you; you are my enduring source of happiness. To our staff, Jon, Heather, and Amy: thank you for the vital work you do that gives WTSA the power to serve the nation and the world. To our many friends: thank you for your support, shared commitment, and high expectations. We want you to be proud of us. In short, to all the members of this remarkable Western community: we are all in this learning tsunami together.

I want to finish with a number and a quotation from one of the fastest men in the world, Maurice Greene. The number is 30,000 . This is the average number of days we have in our 
lifetime, and I have spent 18,000 of mine. If you have a smartphone, you can compute my age. I am wondering what am I going to do with the remaining days-what are you going to do with your days? "Every morning in Africa, a gazelle wakes up. It knows it must run faster than the fastest lion or it will be killed. Every morning, a lion wakes up, and it knows it must run faster than the slowest gazelle or it will starve to death. It does not matter if you are a lion or a gazelle-when the sun comes up, you better be running!" We have a great deal to accomplish, and the world is waiting. From an eyeball engineer, let us start running!

\section{References}

1. Wolf M. The birth of an alphabet and Socrates' protest. In: Proust and the Squid: The Story and Science of the Reading Brain. New York: Harper Collins; 2007: 60-78.
2. Alhassani A, Chandra A, Chernew ME. The sources of the SGR "hole." N Engl J Med. 2012;366:289-91.

3. Christensen CM, Horn MB, Johnson CW. Disruptively deploying computers. In: Disrupting Class: How Disruptive Innovation Will Change the Way the World Learns. New York: McGraw Hill; 2011:96-104.

4. Garfield SR. The delivery of medical care. Sci Am. 1970;222:15-23.

5. Palen TE, Ross C, Powers JD, Xu S. Association of online patient access to clinicians and medical records with use of clinical services. JAMA. 2012;308: 2012-9.

6. Ma J. Think like a scientist. In: The House Advantage: Playing the Odds to Win Big in Business. New York: Palgrave Macmillan; 2010:56-61.

7. Small GW, Moody TD, Siddarth P, Bookheimer SY. Your brain on Google: patterns of cerebral activation during internet searching. Am J Geriatr Psychiatry. 2009;17:116-26.

8. Gardner H. The synthesizing mind. In: Five Minds for the Future. Boston: Harvard Business School; 2007:45-76.

9. Le Grand J. Knights, knaves or pawns? Human behaviour and social policy. J Soc Pol. 1997;26:149-69.

10. Friedman TL. The ten forces that flattened the world. In: The World is Flat: A Brief History of the Twenty-First Century. New York: Farrar, Straus and Giroux; 2005:48-172. 